\title{
How an "Imperative" IS Development was Saved from a Failing Course of Action - A Case Study
}

\author{
Jeremy Fowler, Pat Horan, and Chris Cope \\ La Trobe University, Bendigo, Australia
}

\section{ii2fowler@hotmail.com p.horan@latrobe.edu.au c.cope@latrobe.edu.au}

\begin{abstract}
When an information systems (IS) development project exceeds time, budget and functional constraints a point is reached where the decision has to be made to abandon it or attempt to save it. Some systems are of such value that management is prepared to take extraordinary measures to save them. This paper examines a case study of one such system whose development was saved from likely failure by a combination of good project management, intervention of a business sponsor and a synergistic relationship between management and the system developers. Organizational culture's role in the project's development is also examined in order to present a more holistic view of how the project's successful outcome was generated.
\end{abstract}

Keywords: Information systems' success, information systems' failure, organizational culture, project management.

\section{Introduction}

Many IS development projects end in failure. Some start well but lose their way at some stage during development. However, some systems can be retrieved from impending failure because they are seen by management to be valuable enough to save even at enormous effort and expense. This paper examines one such case of a system whose development was turned from likely failure to success. More specifically, how the interaction between the known success and failure factors and the organization's culture influenced the projects successful outcome is examined. This is an area that has receive little previous attention and provides a more holistic view of the influences of IS success and failure. In order to achieve this aim a single case study of an "imperative" IS was conducted. This case study was guided by the use of critical hermeneutics that acted as both the research's theoretical framework and mode of analysis.

\section{Background}

IS projects continue to fail or are abandoned before their completion at an unacceptable rate (Ewusi-Mensah, 1997; Montealegre \& Keil, 2000; Oz \& Sosik, 2000). These problems persist

Material published as part of this publication, either on-line or in print, is copyrighted by the Informing Science Institute. Permission to make digital or paper copy of part or all of these works for personal or classroom use is granted without fee provided that the copies are not made or distributed for profit or commercial advantage AND that copies 1) bear this notice in full and 2) give the full citation on the first page. It is permissible to abstract these works so long as credit is given. To copy in all other cases or to republish or to post on a server or to redistribute to lists requires specific permission and payment of a fee. Contact Publisher@InformingScience.org to request redistribution permission. despite several decades of research that has tried to explain why failure continues to occur, as well as the development of potential remedies to help alleviate the uncovered problems.

IS researchers' inability to have a significant impact on development success rates may be largely attributed to the areas that they have previously, and currently, been heavily focused on. The 
main focus for researchers has been what is commonly referred to as the factors approach (Sauer, 1999). The factors approach is concerned with discovering those factors most influential in either the success or failure of IS development projects, and the factors that have been consistently uncovered are now well known to the majority of IS personnel. Some of the most commonly reported factors include a lack of top-management support, a lack of adequate user involvement, a lack of effective project management skills and/or involvement, and a lack of the required knowledge and skills in the project personnel (Fowler, 2004).

The factors approach, however, has not led to a significant decrease in the reported instances of IS development failure. The reasons for this may include that:

1. It has not identified the true causes of failure. The identified factors may simply be symptoms of a highly complex problem (Sauer, 1999).

2. The factors are the cause but are not easily avoidable. Organization context and culture may prevent the identified factors from being changed (McBride, 1997; Sauer, 1999; Whyte \& Bytheway, 1996).

3. IS are complex phenomena that cannot be easily explained in such a measurable fashion. It ignores the bigger picture.

This has led researchers to begin to turn away from examining IS predominantly from a factors perspective. Instead, they have started to look at IS success and failure in relation to the organizational culture and context that both directly influences and is directly influenced by the development of IS (Poulymenakou \& Holmes, 1996; Whyte \& Bytheway, 1996). While it is important to examine the factors that appear to be significant in IS success and failure it is equally, if not more, important to look at how these factors react with the organizational culture and context to directly affect project outcomes. No research that looks at developing successful IS and how to avoid failure can achieve many reasonable conclusions unless the issues of culture and context are appropriately addressed (McBride, 1997).

\section{Organizational Culture - The Literature}

Although difficult to define (Hofstede, Neuijen, Ohayy, \& Sanders, 1990; Lee \& Chen, 2005), organizational culture is commonly viewed as a set of commonly shared beliefs, knowledge, attitudes, and customs held by a particular group (Bassi, 1997). Another popular and somewhat more straightforward definition of organizational culture is simply "the way things get done around here" (Deal \& Kennedy, 1982).

Organizational culture governs the conduct of people and how the organization operates in terms of language and communication, work efficiency, meaning of authority, hierarchy and managerial power, strategic change, and creation and utilization of knowledge (Mukama, Kimora, \& Gregory, 2005). Organizational culture has also been shown to play a significant role in information technology management processes (Cabrera et al. 2001) and the management of new IS development projects (Newman \& Sabherwal, 1996).

At the center of organizational culture are assumptions about human nature (e.g. as dishonest or trustworthy), which frequently operate unconsciously and ultimately determine how different organization members perceive their work, treat their customers, and relate to one another (Sikorska-Simmons, 2006). As a system of values, beliefs, and assumptions, culture has a powerful influence on employee work-related attitudes such as job satisfaction, commitment to the organization (Sikorska-Simmons, 2006) and their ability or willingness to adapt and perform well (Bassi, 1997). 
In a broad sense, organizational culture can be seen as having three main important attributes. These attributes are:

1. Direction - determines the course that the culture is causing the organization to flow; that is, is the culture influencing behavior so that organizational goals are accomplished, or is it being counter productive towards the formal mission and goals of the organization?

2. Pervasiveness - the degree to which the culture is widespread, or shared, among the members of a group.

3. Strength - a measure of the amount of pressure the culture exerts on the members of the organization, regardless of direction (Scholl, 2003).

Organizational culture can be supportive or unsupportive, positive or negative (Bassi, 1997), and has the ability to foster behavioral control, encourage organizational stability, and provide the organization with a sense of identity (Scholl, 2003). One way it does this is through establishing the scope of each role in an organization, and by creating distinctive characteristics and variations between organizations (Lee \& Chen, 2005). Paradoxically, organizational culture can be a barrier to organizational change and improvement, a barrier to diversity, a barrier to cross-departmental and cross-organizational cooperation, and a barrier to organizational mergers and acquisitions (Scholl, 2003).

Today, it is commonly believed that organizational culture is responsible for providing the framework to implement and operationalise business strategies (Coolican \& Jackson, 2002). Therefore, management needs to be aware of the culture of which they are a part and put in place strategically appropriate changes where necessary (Igo \& Skitmore, 2005). Otherwise they risk such problems as high employee turnover, poor employee job satisfaction, little or no commitment to anything linked with the organization (Igo \& Skitmore, 2005), and poor information flow among employees and across departmental lines (Abdullah, 2005).

\section{Organizational Culture's Influence on IS:}

Comparatively little research has investigated the influence organizational culture exerts on IS development. However, from the research that has been conducted two key points have arisen:

1. Organizational culture can have a significant impact on the development and operation of IS within an organization (Stair, 1992).

2. IS research suggests that IS projects fail more often for behavioral reasons rather than technical difficulties (Butterfield \& Pendegraft, 1996).

When planning and developing IS organizations need to consider the relationship between the IT initiative and the way it will interact with the organization's culture. An organization's culture must adequately address appropriate human behavioral elements in order to successfully implement IS (Harper \& Utley, 2001). The existing organizational culture's attributes need to be identified and processes put in place to lessen or remove those attributes that prevent or slow successful IS implementation, while paradoxically establishing organizational cultural attributes that support successful IS implementation (Harper \& Utley, 2001).

Pliskin, Romm, Lee, and Webber (1993) made two recommendations in regard to the importance of organizational culture in IS development. The first of these recommendations was to simply be aware of culture. IS designers need to be aware that users can and will attach their own meaning to an IS, independent of the content and the intentions built into the IS's design (Pliskin et al., 1993). The second recommendation is that once developers have become sensitive to the presence of organizational culture they should regard it as a binding constraint in IS implementation. This is because organizational cultures are not built overnight and therefore cannot be changed over- 
night. Therefore, they recommended that IS must be designed to "fit" the current organizational culture (Pliskin et al., 1993). This idea of IS "fit" with an organization is something that several researchers have previously investigated. For example, Cooper (1994) found that some organizational cultures may cause problems when an IS appears to be, or is, in conflict with their current culture. An important point to consider is that developers must not only contend with the organization's culture, they must also be aware of the cultural assumptions that will be intrinsically embedded in the resultant IS (Romm et al., 1991). Therefore, the early detection of any potential culture clash between the IS's embedded cultural assumptions and the organization's culture is required for success (Romm et al., 1991).

Alignment between the organization and the IS is another area that has been found to be vital for IS development success (Middleton \& Harper, 2004). That is, organizational internal practices such as pay, promotion, staff retention, and organizational structure must be in a position to positively support organizational efforts to implement new IS. It has been found that IS projects are likely to fail if the organization does not properly examine and align itself to the change prior to beginning any such innovation (Goulielmos, 2005; Middleton \& Harper, 2004).

In order to deal with the effects culture and other organizational issues place upon IS development, specific IS development methodologies have been developed. Some of the best known of these methodologies include the Soft Systems Methodology (SSM) (Checkland \& Scholes, 1999; Davies \& Ledington, 1999) and the Effective Technical and Human Implementation of Computer-based Systems (ETHICS) methodology (Avison \& Fitzgerald, 2003; Mumford, 1993). These socio-technical systems attempt to give as much attention to people issues, such as cultural and other organizational attributes, as they do to technical issues. For example, the aim of the ETHICS methodology is not necessarily to promote a computer-based solution; but to put the emphasis on participative design with an appropriate balance between the social and computer aspects of systems design (Adman \& Warren, 2000).

The preceding two sections demonstrate that not only is organizational culture a complex issue that plays a significant role in the day to day activities of all organizations; it also has a major effect on the development of IS. But not only that, it is also important to be aware of the influence an IS can have on the culture within which it is implemented. Given this, it becomes evident that organizational culture is an issue that must be addressed by IS developers both to increase their chances of success and also to ensure that the IS is not counterproductive to the culture that is already present in the organization.

\section{Method}

\section{Theoretical Framework}

Critical hermeneutics acts as both the theoretical framework and mode of analysis for this research (Boland, 1991; Bussen \& Myers, 1997; Klein \& Myers, 1999; Lee, 1994; Myers 1994). It is an integrative framework combining interpretive and critical elements and can be treated as both an underlying philosophy for interpretivism and a specific mode of analysis (Bleicher, 1980).

In its most basic terms hermeneutics is the study or science of interpretation (Boland, 1991; Olsen $\&$ Carlisle, 2001). Its primary concern is with the meaning of a text or text-analogue that can be (for example) a book, scholarly article, interview transcript, email, or organization. The basic question in hermeneutics is what is the meaning of this text (Myers, 1994), and the critical hermeneutics tradition holds that in qualitative research there is only interpretation no matter how vocally many researchers may argue that the facts speak for themselves (Denzin \& Lincoln, 2000). 
Critical hermeneutics is a form of interpretive research where researchers begin with the assumption that access to our knowledge of reality is gained only through social constructions such as language, consciousness, shared meanings, documents, tools, and other artifacts (Myers, 1997; Klein and Myers, 1999). In IS, interpretive research is aimed at producing an understanding of the context of the IS and the process by which the IS influences and is influenced by its context (Walsham, 1993). Interpretive research helps researchers to understand human thought and actions in social and organizational contexts and has the potential to produce in-depth insights into many areas of IS research including IS development and IS management (Berntsen, Sampson, \& Österlie, 2004, Klein and Myers, 1999). Interpretive research does not predefine dependent and independent variables, but instead focuses on to the full complexity of human sense making as the situation unfolds (Kaplan and Maxwell, 1994).

A critical hermeneutics approach to the conduct of IS research provides a rich integrative view of IS implementation with the researcher critically evaluating the totality of understandings in a given situation (Myers, 1994). Hermeneutical researchers can transcend the inadequacies of thin descriptions of decontextualized facts and produce thick descriptions of social texts which are characterized by (1) the contexts of their production; (2) the intentions of their producers; and (3) the meanings mobilized in the processes of their construction (Denzin \& Lincoln, 2000).

Critical hermeneutics emphasizes both the subjective meaning for the individual actor and the social structures that condition and enable such meanings (Myers, 1994). This approach overcomes the limitations and narrow, mechanistic perspectives that have tended to dominate the IS implementation literature (Myers, 1994).

\section{Study Design}

A single in-depth case study design was used for this research. As a research endeavor the case study contributes uniquely to our knowledge of individual, organizational, social, and political phenomena (Yin, 1984). It offers a richness and depth of information not generally offered by other research designs (Key, 1997).

\section{Sample}

This research used a purposive sample of fourteen people from a leading Australian organization who were involved in the development of an internet based IS. To select this sample a list of all those involved in the project was first requested from the organization. From this list the people deemed most appropriate based upon their role(s) within the project's development were selected.

The resultant sample consisted of a wide range of people from five organizational departments (based in four locations) with various roles and responsibilities within the system's development. The sample covered a vast majority of the major development actors and stakeholder groups invested in the system's development. These groups included Project Management, IT General, IT Technical, Business, and Executive Management.

\section{Data Collection}

The data collection phase of this research involved a series of semi-structured interviews. These interviews occurred over a period of approximately nine months. Interviews are seen as the most appropriate data collection method in this case because of their suitability in investigating the complex behavior of its subjects and their ability to produce richer data than methods such as questionnaires, surveys, or focus groups (Denzin \& Lincoln, 2000).

The interviews comprised a number of questions relating to five main areas of the system's development. These five areas were: 
1. View of the system's outcome - aimed to elicit each participants view of the overall outcome of the IS and how this outcome compared to other IS developments they had been involved in.

2. View of the system's "imperative" nature - aimed to investigate the perceived importance of the IS to the organization.

3. Cultural factors - aimed to elicit the cultural factors that were the most influential in the various stages of the IS's development. These factors were then compared to the cultural factors each participant felt were the most influential in IS development.

4. Critical factors - aimed to elicit the development factors seen as being most influential in the various stages of the IS's development. These factors were then compared to the factors each participant felt were the more influential in IS development.

5. Changeover - aimed to investigate the phase where some major changes in the system's development structure occurred, and whether each participant felt these changes were a step in the right direction.

\section{Overview of the Case}

The IS project of this study is a large internet based financial transaction service implemented in May of 2003 by a leading Australian-based organization. The system is used by approximately five to six thousand users each day generating somewhere in the order of thirty thousand logons. The system's users cover a broad spectrum of skill levels and frequency of use.

The new system replaced an existing system used by the organization. The objectives of the new system were to (1) replace the existing system with technology aligned with the organization's strategic direction; (2) cater for future growth for a minimum of five years; (3) develop an architecture that provided failover and redundancy; (4) provide a re-use code base that would lower the cost and reduce delivery times of related future development efforts; and (5) train staff in the organization's new application platforms. Of these five objectives, one, three and five have been fully achieved by the implemented system, with objective four being partly achieved. Objective two, cater for future growth for a minimum of five years, is not yet assessable but at this stage looks likely to be fully achieved.

The project's development was planned to take a total of five months and two weeks to complete. In reality the project took approximately seventeen months (an increase of approximately $325 \%$ ) to complete (see Table 1).

Table 1: The project's planned versus actual individual development stage timeframes.

\begin{tabular}{|c|c|c|c|}
\hline \multirow[b]{2}{*}{ Project Stage: } & & \multicolumn{2}{|c|}{ Number of months/weeks (elapsed time) } \\
\hline & & Planned: & Actual: \\
\hline Analysis/planning stage(s) & & 1 month & 3 months 2 weeks \\
\hline Development stage(s) & & 4 months & 12 months \\
\hline Implementation stage(s) & & 2 weeks & 6 weeks \\
\hline & Total: & 5 months 2 weeks & 17 months (approx.) \\
\hline
\end{tabular}

During the project's development a number of significant requirement changes were made including (1) giving the system's interface a totally different look and feel; (2) making several functional changes relating to business service; (3) creating a totally different organizational hardware and network infrastructure; and (4) implementing a number of system fixes. 
The system is now fully operational and is universally regarded within the organization as being highly successful. The organization has also received extensive positive feedback from customers since the system's implementation (Fowler \& Horan 2007).

\section{Case Analysis}

As previously discussed, the case project's initial development had been very problematic. These problems continued for approximately eight months, almost half of the project's total development time.

\section{Problem Areas}

Key problems with its early development mainly revolved around issues regarding the original project management, time estimates, employing contractors who did not have sufficient awareness of the relevant business processes to define the system requirements, and the software related inexperience and geographical dispersion of the project development team. The following sub-sections discuss these problems further.

\section{Project management}

Several crucial problems arose from the initial project management; most of which were not within the project manager's control. The project manager had been selected to run the project despite his lack of any formal software development experience or training. This is a problem that was widespread in the organization at the time. The project manager had been appointed to the task on what was essentially a part time basis only. These two key issues combined to create the clearly undesirable position of having a major software development project headed by a manager who at the time had little experience in this area and was only able to give the project half the attention that it required. This was an unfortunate position not only in terms of the project, but also for the project manager who was required to deal with these contingencies.

\section{Contractors}

The enlisting of external contractors to define and assist in the development of the system also appears to have been a source of many of the difficulties present in the system's development. Because the contractors who defined the system were unfamiliar with the relevant business processes they were unable to adequately define and scope the project. It was also noted that for a period of time under the original project manager the contractors might not have been monitored closely enough and failed to deliver satisfactory results.

\section{Geographical dispersion of the development team}

The geographical dispersion of the development team is seen as another key cause of the project's problematic beginning. Because many of the project development members were located a considerable distance from the organization's main IT center there were many problems related to a lack of adequate communication. These project team members often felt forgotten and cut-off from what was happening and often had trouble getting important information from the organization's main IT center. One team member described it as "like talking to a brick wall."

\section{Inexperience of developers in the technologies used}

The development team also had little or no experience in the programming languages required and spent six months both being trained and teaching themselves, with productivity slowly improving. This had not been factored into the project schedule. In addition, the system was complex and covered new areas many of the project team members had not been exposed to before - 
"it was a far more complicated system than anything we had ever put in before and there were a lot of lessons learned along the way."

These problems appear to have been the key contributors that caused the project's early development to run considerably over its original time and budget constraints. High-level management realized that considerable changes needed to be made in the project's development if it was to avoid continuing on its present failing course. The key changes that occurred during this project restructure included the full-time appointment of an experienced software development project manager coupled with the appointment of a project sponsor from the organization's Business department, who was given ownership of the project. This appears to be the crucial point when success became more likely than failure.

The project manager took corrective action in two spheres, managing the team and implementing a high level of communication with the project sponsor and higher-level management. In managing the team the project manager made communication a high priority. The new manager travelled to the development site, actively involved himself with team members and showed a willingness to act outside his normal job description. He also kept them informed of management views and activities while shielding them from organizational politics. In his relationship with high-level management and the sponsor he ensured frequent communication so they always knew what was happening with the project. Also, procedures that had been informal and undocumented were now formalized.

The business sponsor's function was to keep management and the project manager in tune with the business's vision and needs, thus forming a conduit to ensure that the technical requirements of the project did not become separated from the business' needs. The business sponsor and the project manager developed an excellent working relationship so were able to agree on priorities and actions and present a united front to all participants.

\section{Organizational Culture's Role in the Project's Turnaround}

One of the key organizational cultural factors that allowed the project's development to be turned from failure to success was the organization's uniform recognition of the system's value and importance. This meant that there was consistent support from top-management (in the form of increased resources etc.) right through to the development staff who, by all accounts, were more than willing to put in considerable extra effort in order to achieve both the organization's and their own personal goals.

This key cultural factor was managed via a consistent message to all involved, reinforced from the time of the appointment of the expert project manager and business sponsor who both had high-level access to members of the organization's top-management. The newly appointed project manager worked consistently to keep a high level of communication between all involved organizational departments and management. This helped to foster a communicative culture both among and within the various organizational departments and with high-level management; something that was reported to have been a source of problems in the past. As previously discussed, Scholl (2003) found that such barriers among cross-departmental lines can cause many problems within an organization. The project manager reported that:

Both the business project manager and myself were very careful to keep them [topmanagement] informed... and I had extremely good support... I could probably quote the CEO on that... and his comment basically was that a terrific result had been delivered and it was amazing what could be achieved when IT and Business worked hand-in-hand... so one of the key success factors for me was that Business and IT came together as one team and there was no 'us and them' which is quite common in IT projects. 
This illustrates the importance of the positive alignment of authority, hierarchy, and managerial power as detailed by Mukama et al. (2005).

The project team's perception of their work (e.g. high commitment level and job satisfaction), the positive way they related to one another (Sikorska-Simmons, 2006), and their willingness to learn and adapt (Bassi, 1997) are other cultural factors that had a key influence on the system's successful development. For example, project commitment and job-satisfaction were developed through project management's willingness to empower staff by asking them what they needed in order to complete a required task, rather than simply telling them to complete it. The result of this course of action was that project team members felt that their input was highly valued, and they became empowered and inspired to learn as much as they could about what they were doing, and complete the task to their utmost ability even if that required them to go above and beyond what was normally required. This in turn led to a very high standard of work and employee job satisfaction as well as a decrease in turnaround times. The project manager also supported the team members by acting as a buffer to protect them from the pressure of deadlines and head office requirements.

The methods, techniques, and procedures used in this case helped to achieve a high level of direction, pervasiveness, and strength which, as previously noted, are three of the most important organizational culture attributes (Scholl, 2003). The culture present at the organization at the time of the system's development was strongly directed towards achieving the required tasks and organizational goals. This was especially the case given this project's perceived size, importance, and public visibility. Those involved were aware of the importance of the project to the organization which had a positive influence on the manner in which they approached its development.

...the work ethic that we have here is that people want to do a good job and they get satisfaction out of delivering something that is of benefit to the organization ... and they see what they're doing as having relevance and importance

As well as being a strong positive influence, the organization's culture appeared to be widespread among those involved. All interviewees were very committed to achieving a positive outcome. Although some of this commitment could no doubt be attributed to personal reasons, much of it was brought about by a desire to achieve a positive outcome for the organization.

\section{Conclusion}

Although the system describe here was seen as essential to the organization, its development was allowed to reach a dangerous point where it could have continued on the path to failure. However, because of high-level management commitment and the synergistic conjunction of an excellent project manager, the business sponsor and extensive communication among all participants the project was turned around and moved to success. In the process, much useful learning and skill development occurred and an organizational culture directed to enhancing the company's goals was reinforced.

What is also clear from this case is the crucial importance of the organization's culture in the project's successful turnaround. Organizational culture plays a significant role in IS development and can exert considerable influence on the development factors we generally recognize as influencing project outcomes. IS researchers should strive to include discussions of organizational culture in studies of IS success and failure in order to present more holistic evidence and conclusions. If issues of culture are not adequately addressed then it is likely that useful insights into the reasons for IS success and failure will be missed. 


\section{References}

Abdullah, N. (2005). The influence of leadership on organizational culture and its effects on knowledge management initiative. Retrieved March 12, 2006, from http://ickm.upm.edu.my/presenter1.html

Adman, P. \& Warren, L. (2000). Participatory socio-technical design of organizations and information systems - An adaption of ETHICS methodology. Journal of Information Technology, 39-51.

Avison, D. \& Fitzgerald, G. (2003). Information system development: Methodologies, techniques and tools (3rd ed.). Berkshire: McGraw-Hill Education.

Bassi, L. (1997). Harnessing the power of intellectual capital. In J. Cortada \& J. Woods (Eds.), The Knowledge Management Yearbook 1999-2000. Butterworth-Heinemann.

Berntsen, K., Sampson, J. \& Österlie, T. (2004). Interpretive research methods in computer science. Retrieved August 10, 2006, from http://se.informatik.uni-oldenburg.de/lehre/sose2005/SS04-SeminarMethoden.pdf

Bleicher, J. (1980). Contemporary hermeneutics. London: Routledge \& Kegan Paul.

Boland, R.J. (1991). Information system use as a hermeneutic process. In H.E. Nissen, H.K. Klein, \& R.A. Hirschheim (Eds.), Information systems research: Contemporary approaches and emergent traditions (pp. 439-464). North Holland: Elsevier.

Bussen, W. \& Myers, M. (1997). Executive information systems failure: A New Zealand case study. Journal of Information Technology, 12(2), 145-153.

Butterfield, J. \& Pendegraft, N. (1996). Cultural analysis in IS planning and management. Journal of Systems Management, 47(3), 14-17.

Cabrera, A., Cabrera, E. F. \& Barajas, S. (2001). The key role of organizational culture in a multisystem view of technology-driven change. International Journal of Information Management, 21(3), 245.

Checkland, P. \& Scholes, J. (1999). Soft systems methodology in action. New York: Wiley.

Coolican, M. \& Jackson, J. (2002). Integrating culture with strategy. Retrieved April 23, 2006, from www.leadervalues.com

Cooper, R. (1994). The inertial impact of culture on IT implementation. Information Management, 27, 1731.

Davies, L. \& Ledington, P. (1999). Information in action: Soft systems methodology. Basingstoke, MacMillan.

Deal, T. \& Kennedy, A. (1982). Corporate cultures. Reading, MA: Addison-Wesley.

Denzin, N.K. \& Lincoln, Y.S. (2000). Handbook of Qualitative Research (2nd ed.). Thousand Oaks: Sage Publications, Inc.

Ewusi-Mensah, K. (1997). Critical issues in abandoned information systems development projects. Communications of the ACM, 40(9), 74-83.

Fowler, J. (2004). Factors in information systems' success and failure. (Honors Thesis, La Trobe University, 2004).

Fowler, J. \& Horan, P. (2007). Are information systems' success and failure factors related? - An exploratory study. Journal of Organizational and End User Computing, 19(2), 1-22.

Goulielmos, M. (2005). Applying the organizational failure diagnosis model to the study of information systems failure. Disaster, Prevention and Management, 14(3), 362.

Harper, G. \& Utley, D. (2001). Organizational culture and successful information technology implementation. Engineering Management Journal, 13(2), 11-16.

Hofstede, G., Neuijen, B., Ohayv, D. \& Sanders, G. (1990). Measuring organizational cultures: A qualitative and quantitative study across twenty cases. Administrative Science Quarterly, 35, 285-316. 
Igo, T. \& Skitmore, M. (2005). Diagnosing the organizational culture of an Australian engineering consultancy using the competing values framework. Construction Innovation, 6(2), 121.

Key, J.P. (1997). Research design in occupational education: Module R14 qualitative research. Retrieved January 23, 2006, from http://www.okstate.edu/ag/agedcm4h/academic/aged5980a/5980/newpage21.htm

Klein, H. \& Myers, M. (1999). A set of principles for conducting and evaluating interpretive field studies in information systems. MIS Quarterly, 23(1), 67-93.

Lee, A. (1994). Electronic mail as a medium for rich communication: An empirical investigation using hermeneutic interpretation. MIS Quarterly, 18(2), 143-157.

Lee, C. \& Chen, W.J. (2005). Management in the information technology industry. International Journal of Management, 22(4), 661.

McBride, N. (1997). The rise and fall of an executive information system: A case study. Information Systems Journal, 7(4), 277-287.

Middleton, P. \& Harper, K. (2004). Organizational alignment: A precondition for information systems success? Journal of Change Management, 4(4), 327-338.

Montealegre, R. \& Keil, M. (2000). De-escalating information technology projects: Lessons from the Denver International Airport. MIS Quarterly, 24(3), 417-447.

Mukama, F., Kimora, H. \& Gregory, J. (2005). Organizational culture and its impact in information systems development and implementation: A case from the health information system in Tanzania. Proceedings of the IRIS 28, Kristiansand, August 6-8, 2005.

Myers, M.D. (1994). A disaster for everyone to see: An interpretive analysis of a failed IS project. Accounting, Management and Information Technology, 4(4), 186-201.

Myers, M.D. (1997). Qualitative research in information systems. Retrieved October 25, 2005, from http://www.qual.auckland.ac.nz

Newman, M. \& Sabherwal, R. (1996). Determinants of commitment to information systems development: A longitudinal investigation. MIS Quarterly, 28(1), 23-54.

Oz, E. \& Sosik, J.J. (2000). Why information systems projects are abandoned: A leadership and communication theory and exploratory study. Journal of Computer Information Systems, 41(1), 66-78.

Pliskin, N., Romm, T., Lee, A. S. \& Weber, Y. (1993). Presumed versus actual organizational culture: Managerial implications for implementation of information systems. The Computer Journal, 36 (2), 143-152.

Poulymenakou, A. \& Holmes, A. (1996). A contingency framework for the investigation of information systems failure. European Journal of Information Systems, 5(1), 34-46.

Romm, T., Pliskin, N., Weber, Y. \& Lee, A. (1991). Identifying organizational culture clash in MIS implementation: When is it worth the effort? Information Management, 21, 99-109.

Sauer, C. (1999). Why information systems fail: A case study approach. Oxfordshire: Alfred Waller Ltd.

Scholl, R. (2003). Organizational culture and the social inducement system. Retrieved August 5, 2005, from http://www.cba.uri.edu/scholl/Notes/Culture.html

Sikorska-Simmons, E. (2006). Organizational culture and work-related attitudes among staff in assisted living. Journal of Gerontological Nursing, 32(2), 19-27.

Stair, R.M. (1992). Principles of information systems. Boston, MA: Boyd \& Fraser.

Walsham, G. (1993). Interpreting information systems in organizations. Chichester: Wiley.

Whyte, G. \& Bytheway, A. (1996). Factors affecting information systems' success. International Journal of Service Industry Management, 7(1), 74-93. 
Yin, R.K. (1984). Case study research: Design and methods. California: SAGE Publications.

\section{Biographies}

Jeremy Fowler has a Bachelor of Computing (Honors) degree from La Trobe University and is currently completing his Master of Science degree at the same institution. His current research involves the investigation of the interaction between the cultural and known success and failure factors within an information system that went from a failing course of action to success during its development. It is hoped that this research will help to improve our understanding of information systems development failure through better understanding of the interactions that occur between the cultural and known success and failure factors.

Pat Horan is a Senior Lecturer in the Department of Computer Science and Computer Engineering, Bendigo Section, of La Trobe University. She holds a PhD in Education from Monash University. Her research interests include information systems education, information systems failure and success, and soft systems approaches to systems development.

Chris Cope is a Senior Lecturer at La Trobe University, Bendigo. He holds a PhD in Education from La Trobe University. His research interests include improving teaching and learning about threshold concepts in information systems as well as "simple" frameworks for using ICTs in learning activities to enhance the quality of students' learning outcomes. 